\title{
Law, Society, and Culture in China
}

\author{
Philip C. C. Huang and Kathryn Bernhardt, Editors
}

THE OPENING OF archives on legal case records and judi-

1 cial administration in China has made possible a new examination of past assumptions about the Chinese justice system. Scholars can now ask where actual legal practice deviated from official and popular conceptualizations and depictions. In the process, they can arrive at a new understanding not only of the legal system, but of state-society relations and the nature of the Chinese socialpolitical system as a whole.

Studies of Chinese justice also permit the joining together of social and cultural history. Historians of society and economy, on the one hand, and of mentalities and culture, on the other, have long tended to go their separate ways. Law, however, is a sphere of life in which the two are inseparable. Legal case records contain evidence for both practice and representation. A study of law can tell us about the interconnections between actions and attitudes in ways that segmented studies of each cannot.

The series comprises major new studies by the editors themselves, as well as other contributions from a new generation of scholarship, grounded both in the archives and in new theoretical approaches. 



\section{Social Power}

and Legal Culture

Litigation Masters in Late Imperial China

Melissa Macauley 
Stanford University Press

Stanford, California

(C) 1998 by the Board of Trustees of the

Leland Stanford Junior University

Printed in the United States of America

CIP data appear at the end of the book 
For William M. Macauley, Sr. 
